\begin{tabular}{|c|c|c|c|}
\hline \multirow{3}{*}{$\begin{array}{r}\text { Case Reports in } \\
\text { Gastroenterology }\end{array}$} & \multirow{2}{*}{\multicolumn{2}{|c|}{ Case Rep Gastroenterol 2017;11:277-283 }} & \multirow[b]{3}{*}{$\begin{array}{l}\text { Karger } \\
\text { Open access }\end{array}$} \\
\hline & & & \\
\hline & $\begin{array}{l}\text { DOI: 10.1159/000475754 } \\
\text { Publisned onlIne: IVay 17, } 2017\end{array}$ & $\begin{array}{l}\text { C } 2017 \text { The Author(s) } \\
\text { Published by S. Karger AG, Basel } \\
\text { www.karger.com/crg }\end{array}$ & \\
\hline & $\begin{array}{l}\text { This article is licensed under } t \\
\text { International License (CC BY-N } \\
\text { Usage and distribution for comm }\end{array}$ & $\begin{array}{l}\text { mons Attribution-NonCommercial } 4.0 \\
\text { rger.com/Services/OpenAccessLicense). } \\
\text { quires written permission. }\end{array}$ & \\
\hline
\end{tabular}

\title{
Biliary-Pleural Fistula following Portal Vein Embolization for Perihilar Cholangiocarcinoma
}

\author{
Mujtaba Mohammed Katsuhiro Kobayashi Mohammed Jawed \\ Department of Radiology, SUNY Upstate Medical University, Syracuse, NY, USA
}

\section{Keywords}

Biliary-pleural fistula $\cdot$ Portal vein embolization $\cdot$ Hilar cholangiocarcinoma $\cdot$ Obstructive jaundice

\begin{abstract}
Biliary-pleural fistula (BPF), an abnormal communication between the biliary tract and pleural space, is a rare but potentially life-threatening complication following percutaneous biliary intervention. We report a case of BPF following portal vein embolization (PVE) in a 79-yearold woman with obstructive jaundice secondary to perihilar cholangiocarcinoma. The patient successfully underwent right-sided PVE; however, the patient developed a symptomatic right-sided bilious pleural effusion the following day. Despite aggressive drainage of the pleural effusion with a large-bore chest tube and maximal medical management, the patient died from respiratory failure and pneumonia. Although rare, knowledge of this complication is important when performing PVE in patients with biliary obstruction because it can be lifethreatening. Early recognition and management of this complication are crucial to avoid a poor outcome.

(C) 2017 The Author(s)

Published by S. Karger AG, Basel
\end{abstract}

\section{Introduction}

Portal vein embolization (PVE) is a technique used to induce hypertrophy of a future liver remnant (FLR) prior to major hepatic resection. The wide-spread use of this technique 
is not only due to its usefulness in lowering the risk of liver failure after hepatectomy for patients with a smaller than desired FLR but also due to its safety profile. The reported major complication rates are $<3.0 \%[1,2]$, and complications that result in mortality are extremely rare. Biliary-pleural fistula (BPF), an abnormal communication between the biliary tract and pleural space, is a rare but potentially life-threatening complication of disease of the biliary tract. It has been reported to occur following percutaneous biliary interventions such as transhepatic biliary drainage [3-7] or radiofrequency ablation of a liver tumor [8]; however, it has not been reported as a complication of PVE to our knowledge. Herein, we report a patient with obstructive jaundice secondary to perihilar cholangiocarcinoma who developed a BPF following PVE. The patient developed acute respiratory failure resulting from a progressive bilious pleural effusion, which eventually led to death. We describe this potentially life-threatening complication following PVE and discuss a potential pitfall of PVE when applying this technique to patients with biliary obstruction.

\section{Case Presentation}

A 79-year-old woman with no prior history of malignancy presented to an outside hospital with painless jaundice. Magnetic resonance (MR) images of the abdomen revealed a 4$\mathrm{cm}$ perihilar mass in the right liver extending to the common hepatic duct (Fig. 1). MR cholangiography showed dilated right and left intrahepatic biliary trees without communication between them. The patient underwent endoscopic retrograde cholangiography with cytologic brushing of the common hepatic duct. A plastic stent was placed across the narrowed common hepatic duct with the distal end within the left hepatic duct for internal drainage. Brush cytology and percutaneous needle biopsy of the perihilar mass were positive for poorly differentiated adenocarcinoma. The patient was then referred to our facility with the diagnosis of perihilar cholangiocarcinoma. Laboratory tests at the time of referral showed a total bilirubin level of $7.6 \mathrm{mg} / \mathrm{dL}$ with levels of aspartate aminotransferase $116 \mathrm{U} / \mathrm{L}$, alanine aminotransferase $182 \mathrm{U} / \mathrm{L}$, and alkaline phosphatase 1,068 U/L.

Following meticulous imaging review and discussion at our multidisciplinary conference, a right hepatectomy extended to segment 4B was planned. Because the volume of the FLR was $21.7 \%$ of the estimated total liver volume, the patient was referred to interventional radiology for right-sided PVE. The patient underwent right-sided PVE with an ipsilateral approach when her bilirubin level decreased to $6.9 \mathrm{mg} / \mathrm{dL}$. A posterior branch of the right portal vein was accessed at the mid-axillary line under ultrasound guidance, and the right portal venous system was embolized with 300-500- $\mu \mathrm{m}$ Tris-acryl gelatin microspheres (Embospheres, Biosphere Medical, Rockland, MA, USA) and microcoils (3-5 and 4-10 mm Tornado, Cook Medical, Bloomington, IN, USA). The portal vein access tract was embolized with Gelfoam slurry (gelatin sponge, Pfizer, Kalamazoo, MI, USA).

The immediate postprocedural course was uneventful; however, the patient complained of right-sided abdominal and chest pain the following day. CT of the chest demonstrated a right-sided pleural effusion and a right-sided subphrenic fluid collection (Fig. 2). Thoracentesis yielded $520 \mathrm{~mL}$ of an amber viscous fluid. The fluid culture did not show any bacteria. The patient was discharged home following a 6-day course of prophylactic intravenous antibiotics and symptomatic relief.

Three weeks after PVE, the patient was readmitted to our hospital with recurrent rightsided, upper, abdominal pain and shortness of breath. A chest X-ray revealed a large rightsided pleural effusion (Fig. 3). A 28-Fr chest tube was placed, and amber viscous fluid was 
drained. The fluid analyses indicated bile with a high white blood cell count. A fluid culture showed gram-negative rods of gastrointestinal origin. Based on the clinical course and pleural fluid analyses, a diagnosis of BPF with an empyema was established. To facilitate bile drainage from the liver, a 10-Fr external biliary drain was placed within the right intrahepatic bile duct, and the biliary plastic stent was exchanged via an endoscopic approach. Despite maximal medical management, the patient's clinical condition continued to deteriorate. She developed respiratory failure and pneumonia requiring mechanical ventilation. According to the family's wishes, palliative care was instituted. She died 6 weeks after PVE. The family declined an autopsy.

\section{Discussion}

Historically, BPF has been reported as a complication of thoracoabdominal trauma or parasitic liver disease [9]. Although rare, this condition has recently been reported as a complication of percutaneous biliary interventions such as transhepatic biliary drainage $[3,4,6$, 10], gallbladder drainage [5], or radiofrequency ablation of a liver tumor [8]. Carrasco et al. [6] observed 4 cases (2.5\%) of BPF among 161 patients who underwent percutaneous biliary drainage for malignant biliary obstruction. Biliary obstruction was a common factor in all reported cases of BPF following biliary intervention. The exact mechanism of formation of BPF in our case is unknown due to the lack of autopsy. We observed bile leakage into both right-sided subphrenic and pleural spaces the day after PVE.

Although we used caution not to disturb the intrahepatic bile ducts while gaining access to the peripheral portal vein during PVE, the possibility of biliary system violation remains, as the branches of the portal vein run closely parallel to those of the bile duct as a component of a portal triad. In addition, the risk of biliary system violation would be higher when the system is obstructed. We embolized the portal vein access tract with Gelfoam slurry; however, bile could have leaked into the subphrenic space through the tract due to presumably high pressure within the obstructed right intrahepatic biliary system. Two possible mechanisms could cause bile leakage into the right pleural space. One possible mechanism is that bile leakage occurred through the portal access tract, which could have transgressed the pleural space. Some authors have explained this mechanism as a cause of BPFs following percutaneous biliary drainage $[3,4,7]$. Another possible mechanism is that bile leakage occurred though small diaphragmatic defects via the same mechanism of passage of ascetic fluid through the diaphragm seen in hepatic hydrothorax.

In patients with obstructive jaundice secondary to perihilar hepatobiliary malignancies, selective biliary drainage only on the side of the FLR prior to PVE is advocated due to its superiority to total biliary drainage in promoting hypertrophy of the FLR [11]. Biliary stenting in the left hepatic duct in our case is consistent with this strategy. However, when using this strategy, a theoretical risk of BPF would exist when performing PVE with an ipsilateral approach due to the possibility of accessing the non-decompressed intrahepatic biliary system within the liver. It is not our intention to advocate a contralateral approach in this setting because an ipsilateral approach has been used in many centers for patients with biliary malignancy $[12,13]$, and BPF has not been reported previously to our knowledge. Nonetheless, we suggest great care should be exercised not to disturb the biliary system when performing PVE with an ipsilateral approach in patients with biliary obstruction.

The poor outcome of our case may in part be due to the delay in diagnosis and aggressive treatment of BPF. Rapid drainage of bilious pleural effusion, maximum biliary decom- 
pression, prophylactic antibiotics, and the possible use of somatostatin have been recommended as initial treatments $[3,4]$. We placed an external biliary drain within the right intrahepatic bile duct to maximize biliary drainage; however, due to separation of the right intrahepatic biliary trees by perihilar tumor extension, this measure was minimally effective.

In conclusion, we observed a BPF as a complication of PVE in a patient with biliary obstruction. Although rare, we believe that knowledge of this complication is important because it can be life-threatening, and early recognition and management of this condition are crucial to avoid a poor outcome.

\section{Statement of Ethics}

The authors have no ethical conflicts to disclose.

\section{Disclosure Statement}

The authors have no conflicts of interest to disclose.

\section{References}

1 Abulkhir A, Limongelli P, Healey AJ, et al: Preoperative portal vein embolization for major liver resection: a meta-analysis. Ann Surg 2008;247:49-57.

2 van Lienden KP, van den Esschert JW, de Graaf W, et al: Portal vein embolization before liver resection: a systematic review. Cardiovasc Intervent Radiol 2013;36:25-34.

-3 Turkington RC, Leggett JJ, Hurwitz J, Eatock MM: Cholethorax following percutaneous transhepatic biliary drainage. Ulster Med J 2007;76:112-113.

4 Strange C, Allen ML, Freedland PN, Cunningham J, Sahn SA: Biliopleural fistula as a complication of percutaneous biliary drainage: experimental evidence for pleural inflammation. Am Rev Respir Dis 1988;137:959-961.

5 Lee MT, Hsi SC, Hu P, Liu KY: Biliopleural fistula: a rare complication of percutaneous transhepatic gallbladder drainage. World J Gastroenterol 2007;13:3268-3270.

6 Carrasco CH, Zornoza J, Bechtel WJ: Malignant biliary obstruction: complications of percutaneous biliary drainage. Radiology 1984;152:343-346.

7 Dasmahapatra HK, Pepper JR: Bronchopleurobiliary fistula. A complication of intrahepatic biliary stent migration. Chest 1988;94:874-875.

$\checkmark 8$ Liberale G, Delhaye M, Ansay J, et al: Biliary pleural fistula as a complication of radiofrequency ablation for liver metastasis. Acta Chir Belg 2004;104:448-450.

-9 Ferguson TB, Burford TH: Pleurobiliary and bronchobiliary fistulas. Surgical management. Arch Surg 1967;95:380-386.

10 Herschman Z, Amin D, Lehrfield A: Bilious pleural effusion as a complication of attempted percutaneous biliary drainage. Crit Care Med 1991;19:128-129.

11 Ishizawa T, Hasegawa K, Sano K, Imamura H, Kokudo N, Makuuchi M: Selective versus total biliary drainage for obstructive jaundice caused by a hepatobiliary malignancy. Am J Surg 2007;193:149-154.

$\checkmark 12$ Higuchi R, Yamamoto M: Indications for portal vein embolization in perihilar cholangiocarcinoma. J Hepatobiliary Pancreat Sci 2014;21:542-549.

13 Ebata T, Yokoyama Y, Igami T, Sugawara G, Takahashi Y, Nagino M: Portal vein embolization before extended hepatectomy for biliary cancer: current technique and review of 494 consecutive embolizations. Dig Surg 2012;29:23-29. 


\section{Case Reports in Gastroenterology}
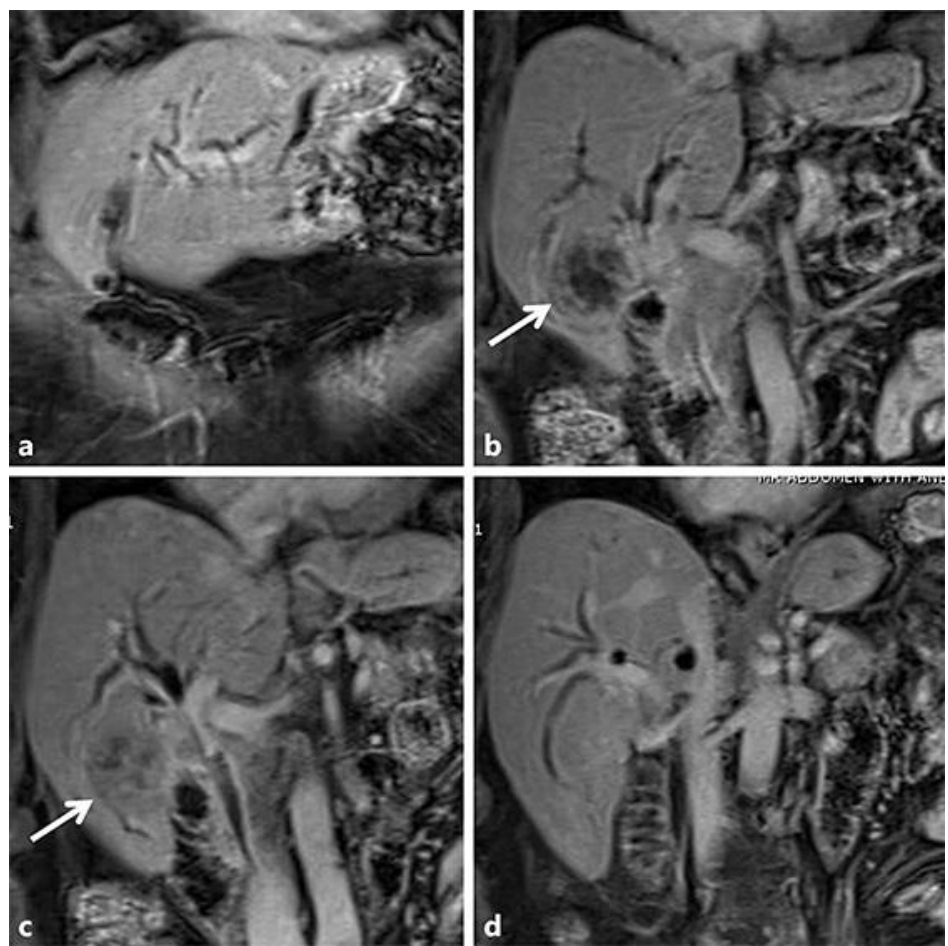

Fig. 1. Coronal contrast-enhanced MR images (a-d) show a 4-cm perihilar mass (arrows in $\mathbf{b}$ and $\mathbf{c}$ ) in the right liver extending to the common hepatic duct. Dilated intrahepatic bile ducts are also seen. 


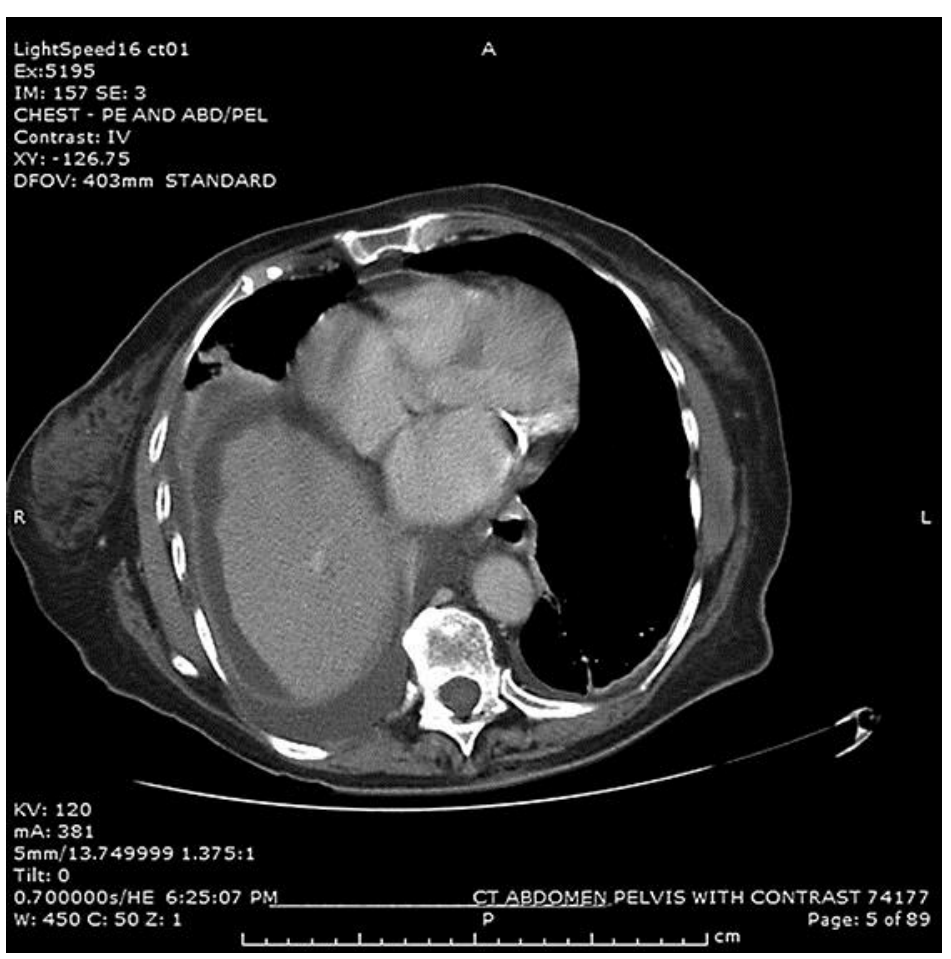

Fig. 2. Axial contrast-enhanced CT at the level of the right hemidiaphragm shows a right-sided pleural effusion and right-sided subphrenic fluid collection. 


\section{Case Reports in Gastroenterology}

\begin{tabular}{l|l}
\hline Case Rep Gastroenterol 2017;11:277-283 \\
\hline DOI: 10.1159/000475754 & $\begin{array}{l}\text { C 2017 The Author(s). Published by S. Karger AG, Basel } \\
\text { www.karger.com/crg }\end{array}$ \\
\hline
\end{tabular}

Mohammed et al.: Biliary-Pleural Fistula following Portal Vein Embolization for Perihilar Cholangiocarcinoma

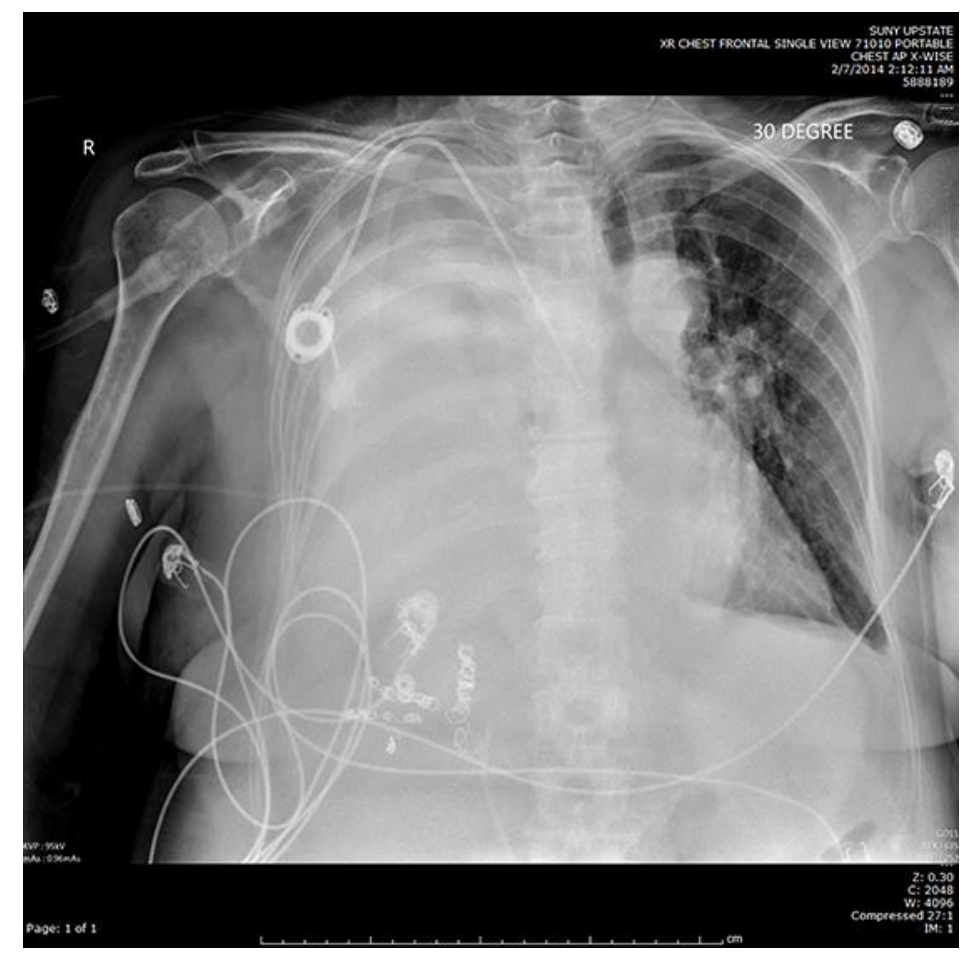

Fig. 3. A frontal chest radiograph shows a large amount of a right-sided pleural effusion. Metallic coils, which were placed within the right portal vein branches during PVE, are also visible in the right upper abdomen. 